\title{
ERRATUM
}

Leonard V. Polishchuk · Jacobus Vijverberg

\section{Contribution analysis of body mass dynamics in Daphnia}

Published online: 16 August 2005

(C) Springer-Verlag 2005

\section{Oecologia (2005) 144: 268-277}

Unfortunately Eq. 6 was incorrectly given. The equation is given correctly below:

$\Delta C_{\mathrm{t}} \cong v \Delta D+E \Delta C_{\mathrm{e}}+C_{\mathrm{e}} \Delta E$

The online version of the original article can be found at http://dx.doi.org/10.1007/s00442-005-0072-x

L. V. Polishchuk $(\bowtie) \cdot J$. Vijverberg

Department of Food Web Studies,

Netherlands Institute of Ecology (NIOO-KNAW),

Centre for Limnology, Rijksstraatweg 6,

3631 Nieuwersluis, The Netherlands

E-mail: leonard_polishchuk@hotmail.com

Tel.: + 7-95-2627722

L. V. Polishchuk

Department of General Ecology, Biological Faculty,

M.V. Lomonosov Moscow State University,

Moscow, 119899 Russia 